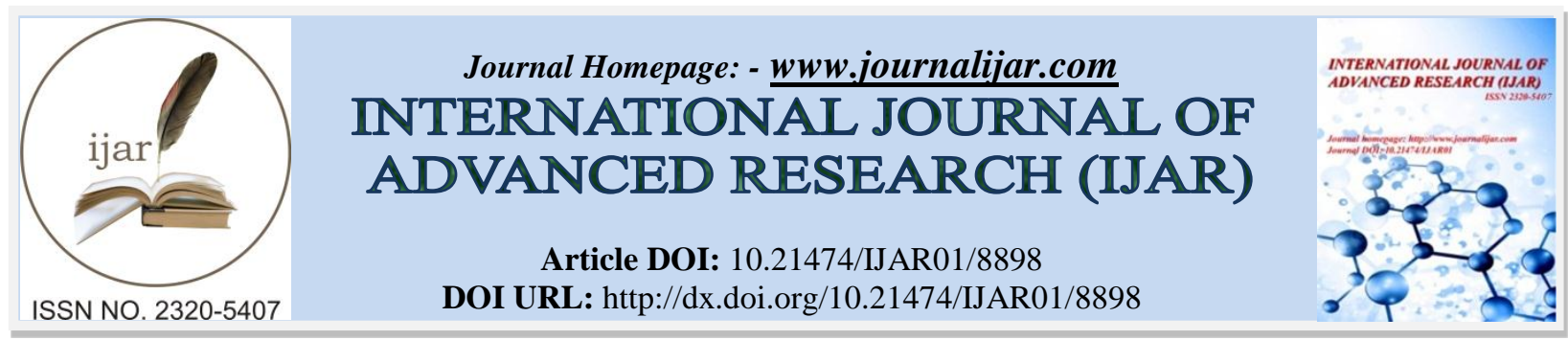

RESEARCH ARTICLE

\title{
ISOLATION OF ENDOPHYTES FROM CASTOR PLANT AND MEASURING ITS ACTIVITY AGAINST HEAVY METALS AND POLLUTANTS.
}

\author{
Ms. Supriya Yadav.
}

Department of microbiology, K. J. Somaiya College of Science and Commerce, Mumbai, India.

\section{Manuscript Info}

Manuscript History

Received: 12 February 2019

Final Accepted: 14 March 2019

Published: April 2019

Key words:-

heavy metals, phytoremediation, castor plant, endophytes, bioaccumulation.

\section{Abstract}

The ever-increasing pollution of the environment has been one of the greatest concerns for science and the general public in the last fifty years. The rapid industrialization of agriculture, expansion of the chemical industry, and the need to generate cheap forms of energy has caused the continuous release of man-made organic chemicals into natural ecosystems. The benefits of combining endophytic bacteria with plants for increased remediation of pollutants have been successfully tried for toxic metal removal from contaminated soils. Endophytic bacteria reside within plant hosts without causing disease symptoms. Several methods have been devised for the treatment and removal of heavy metal in contaminated soils. Biological approach has the great potential that contributed for the bioaccumulation of heavy metals by endophytic bacterial assisted phytoremediation. Three endophytic bacteria were isolated from leaf, stem and root of Ricinus communis . All endophytic bacteria were able to grow at concentration of $5 \% \mathrm{~Pb}$ and $5 \% \mathrm{Zn}$ and could be considered resistant to these metals. The plants which were under heavy metal stress and inoculated with endophytes showed the better growth as compared to control plants. This means that heavy metals are used by the organism for its own metabolism which converts the heavy metals from complex organic compounds into simple byproduct that promotes the growth of the plant. Endophytic association with host moong plants significantly increased the shoot length and biomass as compared to non inoculated control plants. The efficiency of all the three isolate was good in bioremediation of heavy metals. So if these isolates are used in consortium the yield will be more in bioremediation of heavy metals in highly contaminated soil. These isolates can be used as growth promoters in agriculture and also in the soil contaminated with heavy metals and other pollutants.

Copy Right, IJAR, 2019,. All rights reserved.

\section{Introduction:-}

The ever-increasing pollution of the environment has been one of the greatest concerns for science and the general public in the last fifty years. The rapid industrialization of agriculture, expansion of the chemical industry, and the need to generate cheap forms of energy has caused the continuous release of man-made organic chemicals into natural ecosystems. Consequently, the atmosphere, bodies of water, and many soil environments have become India. 
polluted by a large variety of toxic compounds. Metals like cadmium $(\mathrm{Cd})$ and copper $(\mathrm{Cu})$ are added in the agricultural soil during irrigation. These metals have toxic effect on living cells if these metals are present in high concentration. Cadmium can inhibit the growth and yield of plants as a result of chlorosis, instability of lipid membrane, oxidative damage and can react with biochemical functions. Copper is naturally present in the soil which play a vital role in synthesizing enzyme and proteins which are used in various metabolic processes by plants.(Mukti G. et al.,2014). However, if these metals are present in higher concentration can prove toxic for crops because it interferes with numerous physiological process.

This industrial water contain very high amount of heavy metals. These heavy metals and other pollutants have to be removed from the soil through low cost technology before it is applied in agriculture or other purpose. Many methods have been developed to remove the heavy metals like physico-chemicals which include reverse osmosis, solvent extraction, lime coagulation, ion exchange and chemical precipitation which is very expensive. Bioremediation is one such technique which is very efficiently used these days for treatment of heavy metals and other pollutants. Bioremediation is the technique that use microbial metabolism to remove pollutants.

The use of microbe have been reported a good biological absorbents to remove heavy metals. During last decades, a specific techniques such as bioremediation have been evolved which includes phytoremediation enhanced by endophytic microorganisms, rhizoremediation. Endophytes are microorganisms that reside within the inner parts of plants without causing any disease symptoms.Cultivable endophytic communities can be isolated after surface sterilization of the plant material. Endophytes exist in a range of tissue types within a broad range of plants, colonizing the plant systemically with bacterial colonies and biofilms, residing latently in intercellular spaces, inside the vascular tissue or within cells. It has been reported that many isolates provide beneficial effects to their hosts like preventing disease development by synthesizing novel compounds and antifungal metabolites. Investigations of biodiversity of endophyte strains for novel metabolites may identify new drugs for the treatment of human, plant and animal diseases. (Saraswathi M. et al., 2015)

Lack of mobility and solubility of these toxic metals further synergized the negative effect on plant growth. This study provides a new insight into the bioremediation of metal contaminated soil. ( Diby P. et al., 2015)

\section{Materials and Methods:- \\ Sampling:}

Mature and healthy plants will be collected; samples should be processed within 8 hours. Endophytic organisms will be isolated from roots and rhizomes of castor plant. Plant tissue such as leaves stem and roots will be broadly screened for presence of endophytic microbes from castor plant.

Processing of the sample for isolation of the endophytes:

Sampling different parts of the selected castor plant, samples will be taken from roots, stems and leaves.

\section{Disinfecting leaf samples:}

Samples will be immersed in $70 \%$ ethanol for 1-3 min and $4 \%$ aqueous solution of sodium hypochlorite $15 \mathrm{~min}$, $1 \mathrm{~min}$ with $70 \%$ ethanol again and finally rinsed 4-5 times with sterile distilled water.

\section{Disinfecting stem samples:}

With some modification samples will be treated with $70 \%$ ethanol for $3-4 \mathrm{~min}$ and $4 \%$ aqueous solution of sodium hypochlorite $2 \mathrm{~min}, 0.1 \%$ mercury chloride for $1.5 \mathrm{~min}$ and rinsed with sterile distilled water.

\section{Disinfecting root samples:}

Root tissues will be immersed in 70\% ethanol for 1-3min and 5\% aqueous solution of sodium hypochlorite 1 min, 2 min with $70 \%$ ethanol, and 1 min with 0.15 mercury chloride and rinsed with sterile distilled water.

\section{Enrichment of the sample:}

Small disinfected pieces of root, leaves and stem sample was inoculated into 100mL sterile LB medium each. All the three flasks were incubated on shaker conditions at room temperature for 1 week.

\section{Isolation of endophytic bacteria:}


Endophytes were isolated from each of enriched broth onto sterile LB agar plates.Incubated at R.T for 24-48 hours.Pure endophytic cultures were isolated from crowded plates and maintained on fresh nutrient agar medium.

\section{Resistance to heavy metal:}

Minimum Inhibitory Concentration of both the heavy metals i.e $\mathrm{Pb}$ and $\mathrm{Zn}$ in the form of $\mathrm{Pb}\left(\mathrm{NO}_{3}\right)$ and $\mathrm{ZnSO}_{4}$ were checked for all the three isolates. 5\% stock solution of heavy metals $\mathrm{Pb}\left(\mathrm{NO}_{3}\right), \mathrm{ZnSO}_{4}$ was prepared in sterile LB medium. Sterile LB medium without heavy metals were used as a diluents. MIC of all the three isolates i.e R, S and $\mathrm{L}$ were carried out with increasing concentration of both the heavy metals along with positive and negative control. All the tubes were incubated at R.T for 24-48 hours and were checked for the inhibition.

Plant growth promotion: (Ruby J., 2013)

On the basis of result obtained isolates i.e R, S and L was selected and was used for the pot assay. In pot assay different combination of isolates and heavy metals were carried out along with individual isolates, heavy metals and control.

The bioefficacy was determined based on root, shoot length and biomass of the plant. Moong seeds and soil was used as carrier for formulation. The enough amount of healthy monotous seeds of moong were separated by hand and superficial disinfection done with $95 \%$ ethanol within $30 \mathrm{sec}$ and $3 \mathrm{~min}$ in $\mathrm{HgCl}_{2}(0.2 \%)$ and finally were washed with DW at least 4-5min.. Sterile LB media was inoculated with all three endophytic isolates and incubated for 24-72 hrs at R.T. Sterile seeds were coated with inoculated broth and saw with equal distance in the pots. Pots were irrigated with water every day. After interval of 30 days seedlings were removed and shoot length, root length and biomass of the plant were measured.

\section{Result:-}

The three different bacterial species were isolated from different parts of the castor plant and the biochemical tests were performed was done to identify the organisms. Among them one were identified as Bacillus subtilis species and other were identified as Micrococcus luteus and Bacillus species by performing biochemicals.

The isolated endophytic bacteria exhibited tolerance to different heavy metals i.e $\mathrm{Pb}, \mathrm{Zn}$. All endophytic bacteria were able to grow at concentration of $5 \% \mathrm{~Pb}$ and $5 \% \mathrm{Zn}$ and could be considered resistant to these metals. Since the average lead and zinc content of the soil are $0.003 \%$ and $0.02 \%$ respectively, the $5 \%$ of lead and zinc is very high so even if the organisms are not able tolerate this concentration of heavy metals it is not a problem.

To further assess the role of endophyte in improving plant physiology and relieving the adverse effects of $\mathrm{Pb}$ and $\mathrm{Zn}$ stress several parameters like root length, shoot length, leave length and biomass of the plants were determined The bioefficacy was determined based on root, shoot length and biomass of the plant. Moong seeds and soil was used as carrier for formulation. After interval of 30 days all the 12 seedlings from each pot were removed and shoot length, root length and biomass of the plant were measured.

Table No. 1: The average of Root length, Shoot length, Leave length and Weight of all the 12 seedlings from each pot were measured.

\begin{tabular}{|l|l|l|l|l|l|l|l|l|l|l|l|l|}
\hline & Control & $\mathrm{R}$ & $\mathrm{S}$ & $\mathrm{L}$ & $\mathrm{Pb}$ & $\mathrm{Zn}$ & $\mathrm{R}+\mathrm{Pb}$ & $\mathrm{L}+\mathrm{Pb}$ & $\mathrm{S}+\mathrm{Pb}$ & $\mathrm{R}+\mathrm{Zn}$ & $\mathrm{L}+\mathrm{Zn}$ & $\mathrm{S}+\mathrm{Zn}$ \\
\hline $\begin{array}{l}\text { Root } \\
\text { length } \\
\text { (cm) }\end{array}$ & 6.94 & 5.8 & 8.91 & 5.66 & 5.51 & 5.42 & 7.40 & 4.58 & 7.02 & 6.83 & 5.66 & 6.76 \\
\hline $\begin{array}{l}\text { Shoot } \\
\text { length } \\
\text { (cm) }\end{array}$ & 23.6 & 27.4 & 26.33 & 26.66 & 23.25 & 24 & 26.91 & 23.45 & 28.75 & 27.66 & 26.72 & 27.58 \\
\hline $\begin{array}{l}\text { Leave } \\
\text { length } \\
\text { (cm) }\end{array}$ & 2.87 & 3.46 & 3.18 & 3.7 & 2.78 & 2.9 & 3.09 & 3.39 & 3.0 & 3.44 & 3.05 & 3.5 \\
\hline $\begin{array}{l}\text { Weight } \\
\text { (g) }\end{array}$ & 1.104 & 1.627 & 4.15 & 4.633 & 2.960 & 2.308 & 2.738 & 2.508 & 5.080 & 5.404 & 3.686 & 2.755 \\
\hline
\end{tabular}


During $\mathrm{Pb}$ and $\mathrm{Zn}$ stress shoot length, root length, leave length were considerably reduced in endophyte free as compared to endophyte inoculated plants. Increased curling, drying and reduced leaf area was observed in the pots which were not inoculated with endophytes and were under heavy metal stress. This showed that plant was not able to tolerate heavy metals and it had effect on growth and physiology of the plant. The reduced growth of shoot and root was significant in non inoculated pots than in inoculated pots with heavy metals. The plants which were under heavy metal stress and inoculated with endophytes showed the better growth as compared to control plants. This means that heavy metals are used by the organism for its own metabolism which converts the heavy metals from complex organic compounds into simple byproduct that promotes the growth of the plant.Endophytic association with host moong plants significantly increased the shoot length and biomass as compared to non inoculated control plants.

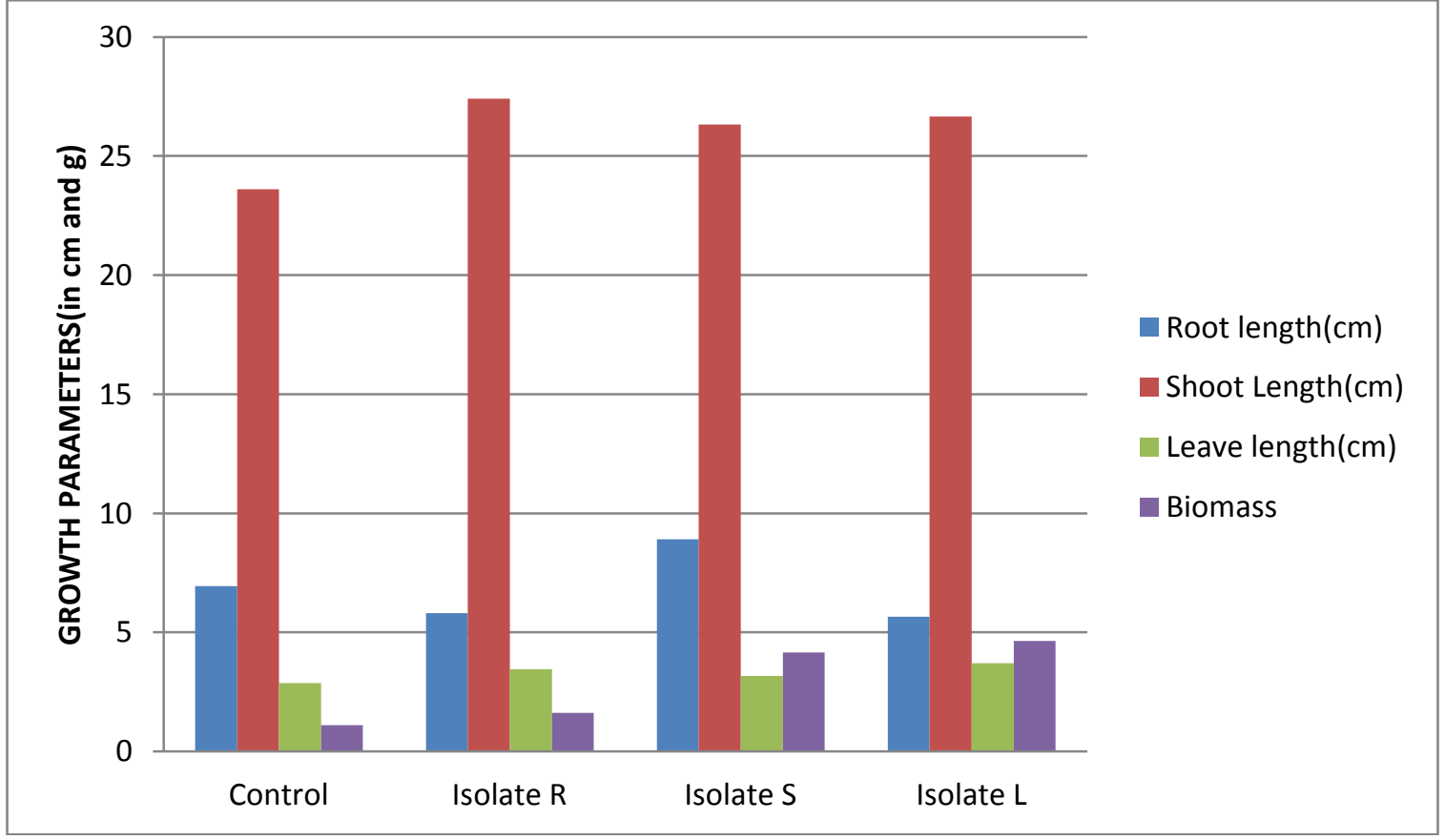

Figure No.1: Growth of plants in presence of endophytes

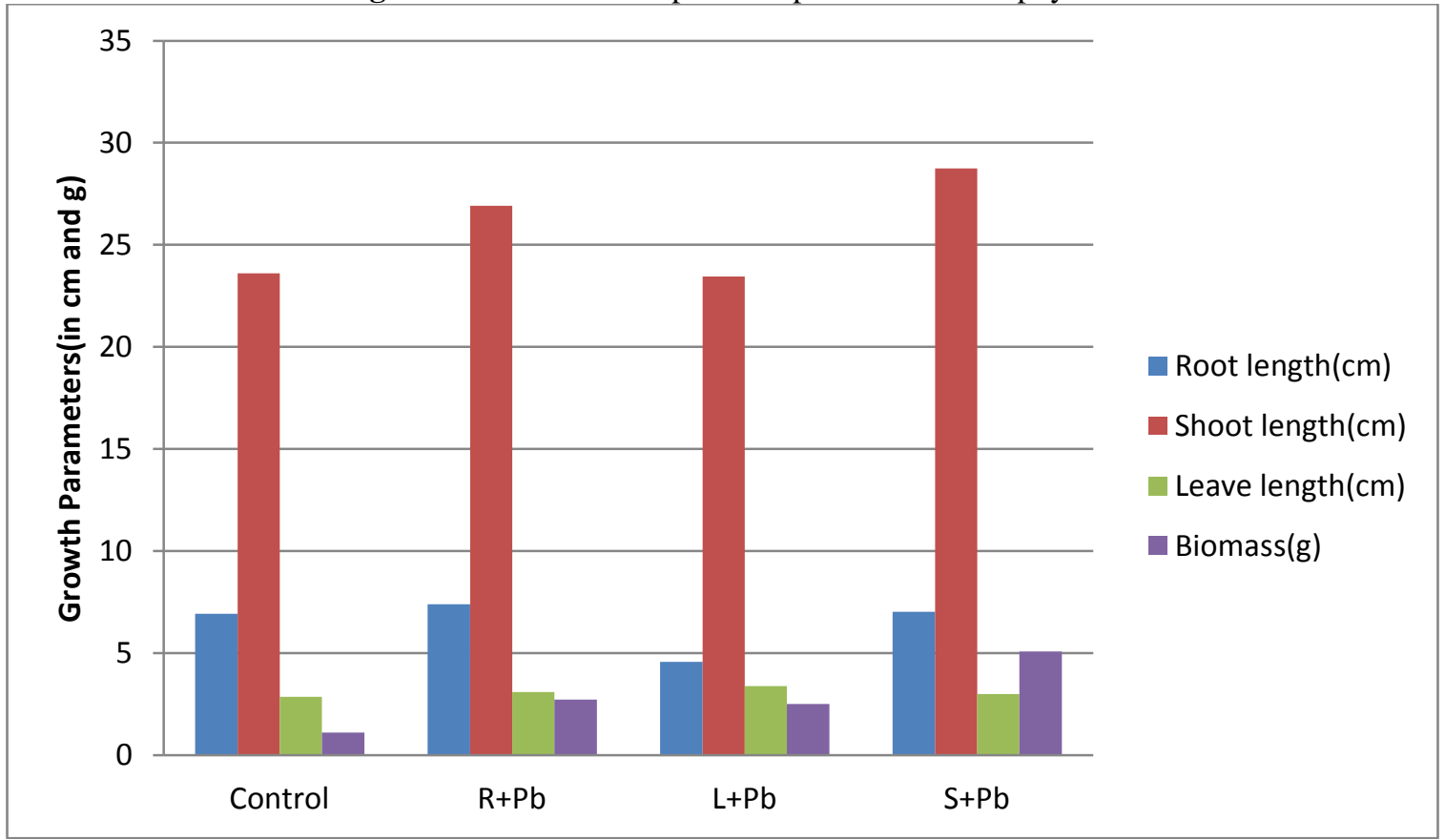

Figure No. 2: Effect of endophytes in $\mathrm{Pb}$ contaminated soil 


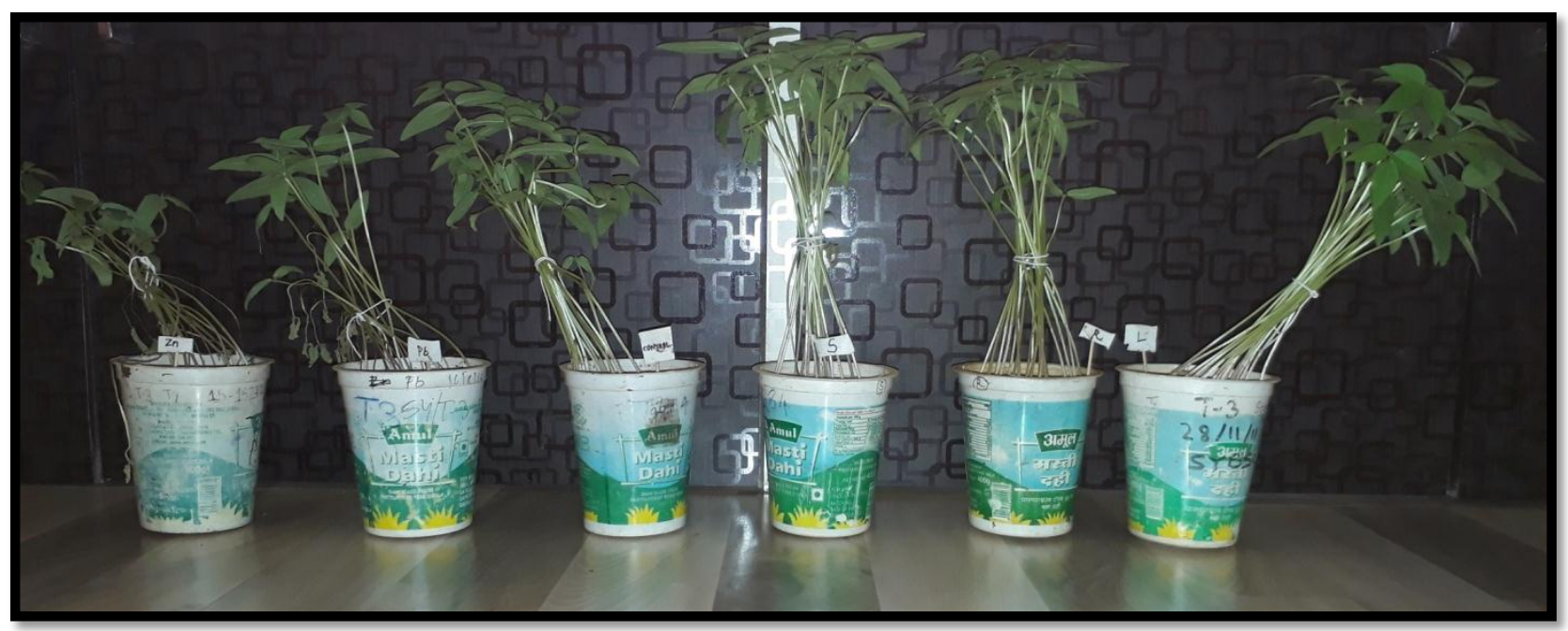

Figure No.3: Growth of plants after 30 days with and without endophytes along with control

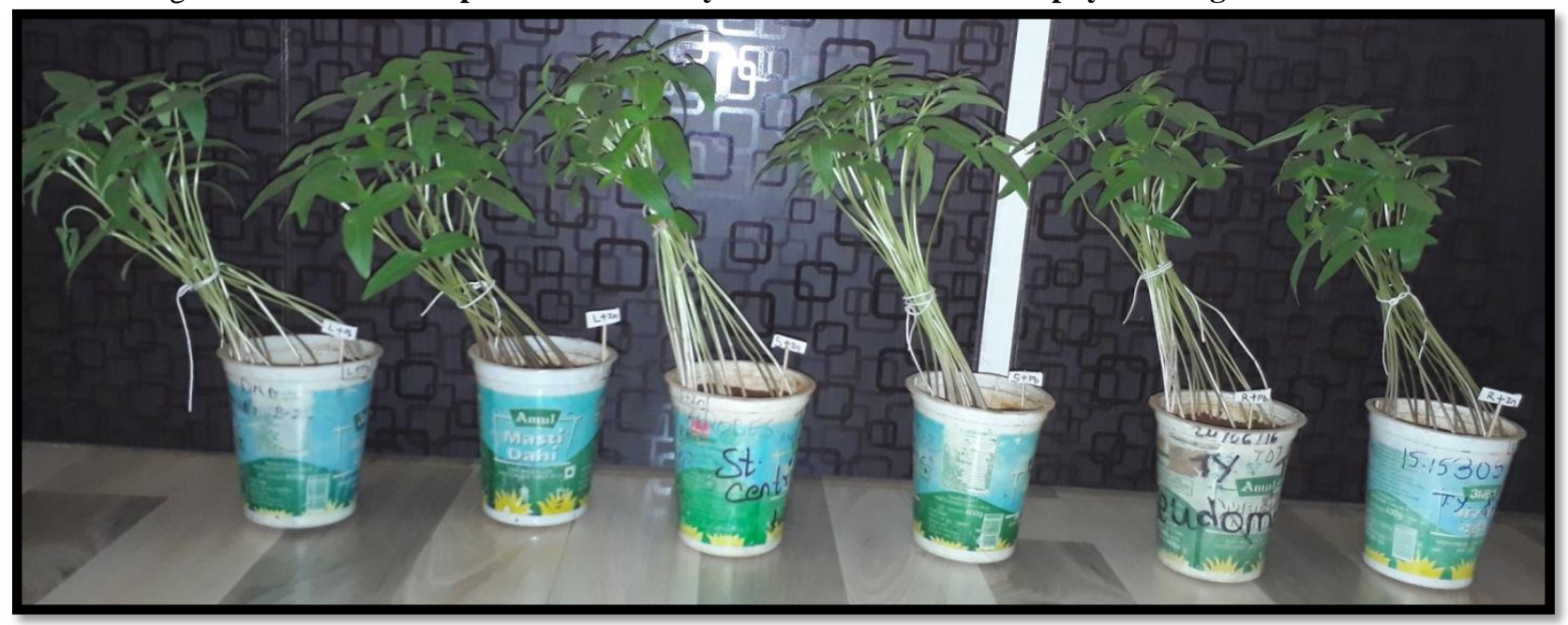

Figure No.4: Growth of plants under heavy metal stress in presence of isolates after 30 days

The plants which were inoculated with endophytes and were not under heavy metal stress showed the best growth. The leaf area was larger than the control plants. The root and shoot length was significantly larger than the control plants. The biomass of the endophyte inoculated plants was much higher than control plants.The pot which was inoculated with isolate $\mathrm{R}$ gave the best shoot length whereas one which was inoculated with isolate $\mathrm{S}$ gave the best root length of the plants as compared to control and other two isolates. In the pot inoculated with isolate L, the biomass of the plant was higher as compared to other two isolates. Also the leave length was more than the results obtained from other two isolates (Table No. 1). Not much difference was seen in shoot length and biomass of the plants which were inoculated with isolate $\mathrm{S}$ and $\mathrm{L}$.

\section{Discussion:-}

Phytoremediation is an environmental friendly, cost effective and plant based solution for the remediation of heavy metal contaminated soils. During phytoremediation, it is an important for plants to continually absorb heavy metals from the soil and transport them from the root to the shoot. Three factors are necessary for this process to be effective: (1) the plants must be resistant to heavy metal; (2) the plants must absorb metals from soil; (3) the metal should be transported from the root to the shoot (Ying Feng et al., 2014).Low biomass production and slow growth of the plants and the low availability of heavy metals in soil limited effective remediation. Effective phytoremediation could be accomplished by bacteria having the potential of solubilizing heavy metals and promoting plant growth in contaminated soils (X-F Sheng et al., 2008). Although plants need some heavy metals as 
essential micronutrients, their excess in soil inhibits plant growth. The heavy metal tolerating capacity of plants mainly depends on plant species or genotype and the concentration of specific heavy metals in the environment (Muhammad Afzal et al, 2015).

In the present study three bacterial endophytes were isolated from root, shoot and leaf interior of the Ricinus communis based on their morphological differences. Tolerance of the isolate towards heavy metal was the first parameter evaluated and all the isolates were able to tolerate these metals upto 5\%. These three isolates showed the resistance to very high concentration of $\mathrm{Pb}$ and $\mathrm{Zn}$. In many other studies $\mathrm{Pb}$ and $\mathrm{Zn}$ resistant bacteria were also isolated; however, they exhibited resistance to comparatively lower concentration of these metals. Similar study showed that the application of the heavy metal-resistant endophytic bacterial strains effectively increased the bioavailability of $\mathrm{Pb}$ in the rhizosphere soils and promoted the growth of rape plants, consequently increasing the total $\mathrm{Pb}$ uptake of the rape plants even under nonsterile conditions.

(Muhammad Afzal et al, 2014; X. F Sheng et al, 2008). Zinc is typically not considered to induce reactive oxygen in plants, however, various studies have demonstrated that zinc can activate copper/zinc superoxide dismutase and proline production to alleviate metal-induced oxidative stress or enhance the activities of antioxidant enzymes. (Ying Feng et al, 2014)

In this study, comparatively less seed germination and root and shoot development was observed with plants cultivated in the heavy metal contaminated soil as compared to the plants vegetated in control soil (Table No. 1). The presence of $\mathrm{Pb}$ and $\mathrm{Zn}$ and other heavy metals in soil reduces seed germination and plant growth. Despite the toxic effects of heavy metals present in the contaminated soil, inoculation of $\mathrm{Pb}$ and $\mathrm{Zn}$-resistant plant growthpromoting bacteria increased seed germination and root and shoot development. Particularly, three individual strains improved plant growth and development to a greater extent. Similarly, it was found that bacterial inoculation reduced $\mathrm{Pb}$ and $\mathrm{Zn}$ toxicity and improved seed germination and plant growth. In this study, the ability of the inoculated endophytic bacteria to improve plant growth in the heavy metal contaminated soil might be due to the combined effect of heavy metal tolerance ability as well as plant growth-promoting activities.

In this study, moong was found to be able to tolerate $\mathrm{Pb}$ and $\mathrm{Zn}$ contaminated soil. The application of $\mathrm{Pb}$ and $\mathrm{Zn}$ resistant plant growth-promoting endophytic bacteria to moong further enhanced the tolerance of $\mathrm{Pb}$ and $\mathrm{Zn}$ from the soil. Similarly, earlier studies reported that the inoculation of $\mathrm{Pb}$ and Zn-resistant plant growth-promoting bacteria enhanced the heavy metals uptake by plants. (Mani Rajkumar et al, 2007). The present study suggests that the use of $\mathrm{Pb}$ and $\mathrm{Zn}$-resistant plant growth-promoting bacteria protects the plant against the inhibitory effects of heavy metals present in the heavy metal contaminated soil and facilitates the transportation of heavy metals from soil in to above ground plant biomass.

In this study the plants which were under heavy metal stress and inoculated with endophytes showed the best growth of plants. There was significance increase in root, shoot, leave length and biomass of the plant as compared to control plants . the plants which were inoculated with only endophytes separately showed the significant increase in root ,shoot,leave length and biomass as compared to control plants. There wre decrease in root,shoot, leave length and biomass of the plant which were inoculated with only heavy metals separately. This means that heavy metals affect the growh and physiology of the plant. The growth of plants hich were under heavy metal stress and inoculated with only endophytes sepately wre much good as compared to plants which were under heavy metal stress.

The endophytic bacteria colonizing the plant tissue interior might protect plant against the inhibitory effects of high concentration of $\mathrm{Pb}$ and $\mathrm{Zn}$ which promotes the plant growth. Several earlier study also reported that this plant can accumulate high concentration of different metals in its roots, shoots and leaves. This might be one of the reasons that Ricinus commuinis hosts several bacteria in its tissue which can tolerate high concentration of heavy metals. (Mani Rajkumar et al, 2007) The findings of the present study suggests that endophytes such as Bacillus circulans, Bacillus subtilis and Microccocus leutus cannot only improve the plant biomass but also resist the toxic effects of metal concentration. Such beneficial impacts may be due to secretion of bioactive compounds which might help in converting metal into stable complexes. However it is also essential to understand the in vivo mechanism by which the bioactive compounds producing endophytes reduce the metal toxicity. 
Plant-bacteria partnerships can be exploited to enhance phytoremediation efficiency of soil and water contaminated with organic and inorganic pollutants. The beneficial effects of heavy metal- resistant and plant growth-promoting bacteria include reduced heavy metals toxicity and accelerated root development, resulting in better access to nutrients and water and thus faster initial growth, leading to enhanced remediation of contaminated soil environmentally and economically sustainable plant biomass production. Improved yields on contaminated land might also reduce the need to clear and use additional areas of land for food, feed fiber and biofuel feedstock production for a growing world population, consequentially saving native ecosystems and biodiversity. Overall, the combined use of plants and bacteria can act as decontaminators by improving phytoremediation or protecting the food chain by decreasing the levels of pesticide residues in crops. (Khan et al., 2015)

In present study, it was found that Ricinus commuinis hosted 3 culturable $\mathrm{Pb}$ and $\mathrm{Zn}$ - resistant bacteria in its interior tissue and their inoculation to moong improved plant growth and the remediation of heavy metal contaminated soil, suggesting their potential use in the remediation of heavy metal contaminated soil. The stimulatory effects of $\mathrm{Pb}$ and Zn-resistant plant growth-promoting endophytic bacteria on moong growth might be due to the additive effects of different plant growth-promoting properties of the isolated endophytic bacteria. Further plant-inoculation experiments in different combinations are needed to better understand the stimulatory effects of the combined inoculation strategy. The very high level of metal tolerance of the isolated bacteria of Ricinus commuinis makes them interesting candidates for further studies on the genes involved in this tolerance. Plants growing on heavy metal contaminated sites could be excellent ecosystems to isolate bacterial genes involved in metal resistance and/or plant growth promotion.

\section{Conclusion:-}

This study investigate the effects of inoculation with the endophytic bacterium, R,S,and L, on plant growth, root morphology, and biomass, a study that might facilitate the understanding of mechanisms of microbe-assisted phytoremediation. Through pot assay, all three bacterial isolate inoculations significantly enhanced the efficiency of zinc and lead phytoextraction by increasing $R$. communis biomass, promoting zinc and lead absorption, improving root, shoot and leave morphology. The application of endophytes to phytoremediation not only strengthens the ability of phyto-accumulators to acclimate to the contaminated environment, but also expands the application range of phytoremediation.

Thus, these promising endophytes may be commercially formulated effective biocontrol agents for the management of heavy metal contamination of the soil. These isolates were further selected for further studies on their effect on plant growth parametes, diseases incidences.

\section{References:-}

1. Abdul Latif Khan and In-Jung Lee.(2013).Endophytic Penicillium funiculosum LHL06 secretes gibberellin that reprograms Glycine max L. growth during copper stress.BMC Plant Biology,13(86),1-14.

2. A.Ramlingam and C.Amutha.(2013). Antibacterial Activity of bacteria associated with Red Seaweeds against pathogenic bacteria of poultry and cattle. International Journal of Environmental Biology. 3(1), February, 2225.

3. Arnold, A.E. and Engelbrecht, B.M.J. (2007).Fungal endophytes nearly double minimum leaf conductance in seedlings of a neotropical tree species. Journal of Tropical Ecology. 23, 369-372.

4. Aldoobie, N. F. and Beltagi, M. S. (2013) Physiological, biochemical and molecular responses of common bean (Phaseolus vulgaris L.) plants to heavy metals stress.African Journal of Biotechnology, 12(9),May ,46144622.

5. Aishwarya.S, Venkateswarlu.N, Chandra mouli.K, Vijaya.T. (2014).Role of Endophytic Fungi in Restoration of Heavy Metal Contaminated Soils .Indo American Journal of Pharmaceutical Research. 4(11), November, 54275435 .

6. Bhore Subhash J, Tiong Oon King. (2012). Bacterial Endophytes of Therapeutically Important Strobilanthes crispa (L.) Bremek and Vernonia amygdalina Del, Journal of Pharmaceutical and Biomedical Sciences.14 (11), August ,1-3.

7. Khan S., Cao Q., Zheng Y.M., Huang Y.Z., Zhu Y.G.(2008).Health risk of heavy metals in contaminated soils and food crops irrigated with waste water in Beijing, China, Environ. Pollut.;152 : 686-692. 
8. Lingan Rajendran, Duraisamy Sarvankumar, Thiruvegadam Raguchander and Ramasamy Samiyappan.(2006) .Endophytic bacterial induction of defence enzymes against bacterial blight of cotton.Phytopathologia Mediterranea.45, December, 203-214

9. Mani Rajkumar, Helena Freitas.(2007).Influence of metal resistant-plant growth-promoting bacteria on the growth of Ricinus communis in soil contaminated with heavy metals.Sciencedirect. 71, November, 834-842.

10. Muhammad U.Khan, AngelaSessitsc, MuhammadHarris, KaneezFatima, AsmaImran, Muhammad Arslan, GhulamShabir, QaiserM.Khan and Muhammad Afzal. (2014). Cr-resistant rhizoand endophytic bacteria associated with Prosopis juliflora and their potential as phytoremediation enhancing agents in metal-degraded soils. Frontiers in Plant Science. 5,1-10.

11. Mukti Gill,(2014).Heavy metal stress in plants. International Journal of Advanced Research. 2 (6)1043-1055.

12. Malik, N. J., Chamon, A. S., Mondal, M. D., Elahi, S.F. and Faiz, S.M.A. (2011): Effect of different levels of zinc on growth and yield of red amaranthus and rice. J. Bangladesh. young Res.. 1(1):79-91

13. Ruby E Jalgaonwala. (2013). Bioprospecting for Microbial Endophytes and their Natural Products. Journal of Soil Science and Plant Nutrition.13(3),44.

14. Xia-Fang Sheng', Juan-Juan Xia, Chun-Yu Jiang, Lin-Yan He, Meng Qian.(2008). Characterization of heavy metal-resistant endophytic bacteria from rape (Brassica napus) roots and their potential in promoting the growth and lead accumulation of rape. Environmental Pollution.156 (3), February, 1164-1170.

15. Z. Stępniewska \& A. Kuźniar.(2013). Endophytic microorganisms—promising applications in bioremediation of greenhouse gases.Applied Microbiology Biotechnology. 97, September, 9589-9596. 